\title{
Fashion entrepreneurial self-efficacy: Development and validation of a domain-specific scale
}

\author{
Chunmin Lang, Chuanlan Liu, Louisiana State University
}

Keywords: fashion, entrepreneurship, self-efficacy, scale, measurement

\section{Introduction}

Economy development strives to create more diverse and vibrant businesses and to sustain economic growth. The cultural-related entrepreneurship establishes a growing source of employment and economic development. The fashion industry, one of the largest consumer industries, with a focus on changes, creative and innovations has great potential to cultivate Micro and Small Enterprises (MSEs). Although the population of fashion entrepreneurs has been increasing notably, many new business ventures are still having difficulties in the start-up stage and struggling to develop practical strategies to grow. Having a belief that one has the ability to succeed is crucial in any task. Selfefficacy is the concept used to explain this belief (BarNir, Watson, \& Hutchins, 2011). Self-efficacy has been found to be positively correlated with academic success (Multon, Brown, \& Lent, 1991) and with the maintenance of exercise participation in older adults (McAuley, 1993).

Training and support services may help increase self-efficacy, which, in turn, may increase one's desire and ability to pursue entrepreneurship. Increasing self-efficacy is critically important for those who wish to pursue an entrepreneurial career in the fashion industry in which fashion life cycles change constantly and there is also a constant demand for new and fresh design concepts, product assortments, and market operations. Merely having a desire to pursue entrepreneurship in the fashion field is not enough. Individuals must feel confident in their ability to start a business in order to do so successfully. One must also be aware of the fashion product life cycle, along with proper lead times and effective merchandising techniques.

Recently, scholars have started calling for specific research on industry-domain-based entrepreneurship. Previous studies (e.g., McGee et al., 2009) have developed a construct for entrepreneurship self-efficacy and test whether an individual's belief in which individual can perform the tasks that are needed to operate a business has an impact on entrepreneurial action, intent, and varying other behaviors. However, the extant literature lacks fashion domain-based entrepreneurship research. As Richardson noted (1996), "fashion apparel is a highly competitive business where product life is short and differentiation advantages are built on brand image and product styling that can be quickly imitated" (p. 400). Researching fashion domain-based entrepreneurship is critical to advocate fashion entrepreneurship. To this end, this project intends to fill the urgent need to develop and validate a multidimensional measurement to assess fashion entrepreneurial self-efficacy. Specifically, the goal is to define and examine the components of fashion entrepreneurship efficacy; to develop effective scales to measure fashion entrepreneurial self-efficacy.

\section{Research method}

The recommended process for scale development (e.g., Churchhill, 1979) was followed: conceptualizing construct definition and specifying domain(s), generating and judging initial items, scale purification, and scale validation. Literature review and in-depth interviews were utilized to develop potential categories and items to measure fashion entrepreneurial self-efficacy. To conduct 
the interview, a snowball sampling method was applied to identify participants who are running small fashion businesses. Participants were invited to attend an individual online interview through Pure Chat online software. The authors conducted 19 individual interviews. Among these interviewed fashion entrepreneurs, three were males and sixteen were females, and their age ranged from 22-56. Most interviews were conducted within 40-60 minutes. All transcripts were reviewed by all authors and discussed to identify initial themes. Then, the primary investigator coded the transcripts from the 19 participants. In addition to the individual interviews, the extensive review of 18 trade articles on the topic of "the ways to become a successful fashion entrepreneur" was also conducted. The individual interview and extensive literature review yielded an initial scale pool of 72 items.

Scale purification-The main purpose of scale purification was to reduce the number of items and initially assess the scale's structure and dimensionality. An online questionnaire was developed that consisted of the 72 items with a 7 -point scale ( $1=$ strongly disagree to $7=$ strongly agree $)$, as well as standard demographic questions. A national sample was recruited through the research company of Qualtrics. We defined the fashion businesses as a business providing fashion related products or services for a profit, such as the sale of new and used fashion products, fashion-related services (e.g. fashion style consultancy, fashion blogs, etc.). Following this definition, a filter question was created to ensure all the participants are currently running or have the intention to run a fashion business. A total of 249 out of 1231 collected responses were considered valid and used for analyses.

Exploratory factor analyses. Along with item analyses, the items were analyzed through exploratory factor analysis (EFA) with principal component analysis using Varimax rotation. Items that demonstrated low communalities (below .40), low factor loadings (below .50), and/or high crossloadings (above .50) were removed. After a few rounds of EFA, a four-factor model with 28 items emerged. These four factors include: Passion for Fashion Business reflects the level of passion people have for fashion and fashion business and to what degree that they will keep doing without giving up when meeting difficulties and problems during the operation of the business. Marketing and Branding refer to the ability to create and promote a brand and branded merchandise in the market. Financial Management refers to the ability to manage finance and obtaining funding for the operation of the business. Creativity refers to the ability to use the imagination or original ideas in the merchandise or content development. The final four-factor model accounted for approximately $71.92 \%$ of the total variance and showed a KMO measure of sampling adequacy of .945. The communalities ranged from .642 to .815 , and factor loadings ranged from .645 to .835 .

Confirmatory factor analyses. The retained 28 items were subjected to a confirmatory factor analysis (CFA) using AMOS 25 in order to assess the congeneric measurement quality of the scale (Netemeyer et al., 2003). Items with high covariance were removed. The final four-factor model has 21 items. The fit indices show good model fit: $\mathrm{CFI}=.964, \mathrm{TLI}=.958, \mathrm{RMSEA}=.056$. Therefore, it was concluded that the model with 21 items was adequate to be the final model in the purification phase - a scale consisting of four dimensions: five items for passion for the fashion business, seven items for marketing and branding, five for financial management, and four for creativity.

\section{Discussion}

This study is the first attempt to develop practical scales measuring self-efficacy that focus on fashion domain-based entrepreneurship. When compared to existing scales that are used to measure entrepreneurial self-efficacy, the four dimensions identified in this study and the items contained in each dimension reflect the typical characteristics in the fashion industry and will be more suitable to fashion entrepreneurs needing to evaluate their potential of running successful fashion businesses.

Page 2 of 3

(c) 2020 The author(s). Published under a Creative Commons Attribution License

(https://creativecommons.org/licenses/by/4.0/), which permits unrestricted use, distribution, and reproduction in any medium, provided the original work is properly cited.

ITAA Proceedings, \#77 - https: //itaaonline.org 


\section{References}

BarNir, A., Watson, W. E., \& Hutchins, H. M. (2011). Mediation and moderated mediation in the relationship among role models, self-efficacy, entrepreneurial career intention, and gender. Journal of Applied Social Psychology, 41(2), 270-297.

Churchill Jr, G. A. (1979). A paradigm for developing better measures of marketing constructs. Journal of marketing research, 16(1), 64-73.

McAuley, E. (1993). Self-efficacy and the maintenance of exercise participation in older adults. Journal of Behavioral Medicine, 16(1), 103-113.

McGee, J. E., Peterson, M., Mueller, S. L., \& Sequeira, J. M. (2009). Entrepreneurial self-efficacy: Refining the measure. ETAP Entrepreneurship Theory and Practice, 33(4), 965-988.

Multon, K. D., Brown, S. D., \& Lent, R. W. (1991). Relation of self-efficacy beliefs to academic outcomes: A meta-analytic investigation. Journal of Counseling Psychology, 38(1), 30-38.

Pasquinelli, I. (2012). Could small be the new big for the fashion industry? Retrieved from https://www.theguardian.com/sustainable-business/blog/fashion-industry-trends-innovationsmall-business

Richardson, J. (1996). Vertical integration and rapid response in fashion apparel. Organization Science: A Journal of the Institute of Management Sciences, 7(4), 400-412. 